\title{
The two faces of spontaneous serotonin signalling
}

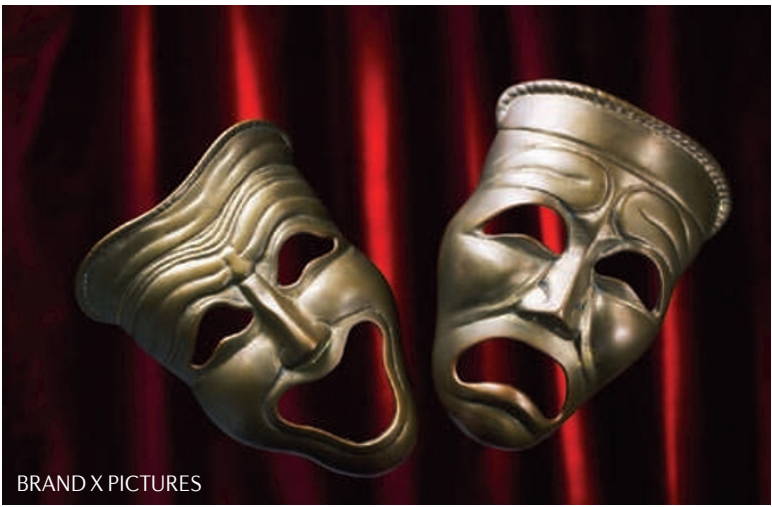

Following spinal cord injury (SCI) there is immediate paralysis of muscles that are innervated by motor neurons caudal to the injury site, which is followed several weeks later by a restoration of motor neuron excitability. This restoration is associated with recovery of motor function but also with debilitating muscle spasms and occurs through an unknown mechanism. Now, Murray et al. show a role for constitutive activation of the 5-hydroxytryptamine (5-HT) receptor $2 \mathrm{C}\left(\underline{5-H T}_{2 \mathrm{C}}\right)$ in this process, and highlight $5-\mathrm{HT}_{2 \mathrm{C}}$ inverse agonism as a potential antispastic therapeutic strategy.

Normally, motor neurons in the spinal cord receive neuromodulatory, including serotonergic, input from brainstem neurons. Activation of 5-HT receptors facilitates various persistent inward currents (PICs) on motor neurons, particularly $\mathrm{Ca}^{2+}$ PICs, leading to sustained motor neuron activity. As loss of this brainstem-derived 5-HT is partly responsible for the muscle paralysis following SCI, the authors proposed constitutive activation of 5-HT receptors as a possible compensatory mechanism by which the body attempts to restore motor function. They focused on the $5-\mathrm{HT}_{2 \mathrm{C}}$ subtype because several $5-\mathrm{HT}_{2 \mathrm{C}}$ isoforms are known to show constitutive activity.

In rats with chronic (6-12-week) SCI, cutaneous electrical stimulation of the tail induced sustained muscle spasms that were unaffected by administration of a $5-\mathrm{HT}_{2 \mathrm{C}}$ antagonist but were significantly inhibited by the $5-\mathrm{HT}_{2 \mathrm{C}}$ inverse agonists SB206553 and cyproheptadine (which block constitutively active $5-\mathrm{HT}_{2 \mathrm{C}}$ receptors), as measured in electromyography and tail flick studies. These findings were reproduced in the isolated spinal cord in vitro, ruling out the possible involvement of peripherally produced 5-HT.

To investigate the influence of constitutively active $5-\mathrm{HT}_{2 \mathrm{C}}$ receptors on $\mathrm{Ca}^{2+}$ PICs, the authors performed intracellular recordings in motor neurons under an increasing voltage ramp and in the presence of tetrodotoxin to block $\mathrm{Na}^{2+}$ currents. The sharp downward deflection in the current response that represents the $\mathrm{Ca}^{2+} \mathrm{PIC}$ was unaffected by the $5-\mathrm{HT}_{2 \mathrm{C}}$ antagonist but was almost abolished by the $5-\mathrm{HT}_{2 \mathrm{C}}$ inverse agonists.

Post-transcriptional modification at five sites of the $5-\mathrm{HT}_{2 \mathrm{C}}$ RNA affects the constitutive activity of the resultant receptor. The authors therefore determined the relative expression of various $5-\mathrm{HT}_{2 \mathrm{C}}$ isoforms, and found that chronic SCI was associated with a $400 \%$ increase in expression of the unedited, constitutively active isoform.

In humans with SCI, leg muscle spasms evoked by cutaneous stimulation to the foot were significantly reduced by oral administration of cyproheptadine. This suggests the potential of inverse agonism of the $5-\mathrm{HT}_{2 \mathrm{C}}$ receptor as a therapeutic strategy to manage the spasticity resulting from chronic SCI. However, recovery of locomotion in rats following partial SCI was inhibited by SB206553, highlighting the need to establish a therapeutic window in which to block only the deleterious effects of constitutive 5- $\mathrm{HT}_{2 \mathrm{C}}$ activity.

Katie Kingwell

ORIGINAL RESEARCH PAPER Murray, K. C. et al. Recovery of motoneuron and locomotor function after spinal cord injury depends on constitutive activity in $5-\mathrm{HT}_{2 \mathrm{C}}$ receptors. Nature Med. 16 694-700 (2010) 